\title{
Covid-19 Lockdown: Psychological Implications on Life Quality
}

\author{
Benita Dooshima Aki ${ }^{{ }^{*}}{ }^{\oplus}$, Emmanuel Lamptey ${ }^{2}{ }^{\circledR}$, Susie Nguemo Hembah ${ }^{1}{ }^{\circledR}$, \\ Oibiokpa Michael Oibiokpa ${ }^{1}$, Tartenger Raymond Tachin ${ }^{1}$ \\ ${ }^{l}$ Department of Psychology, Benue State University Makurdi, Makurdi, Nigeria \\ ${ }^{2}$ Institute of Life and Earth Sciences (including Health and Agriculture), Pan African University, University of Ibadan, Oyo State, Nigeria
}

Received 19 February 2020; Revised 12 May 2020; Accepted 20 May 2020; Published 01 June 2020

\begin{abstract}
Being a new infection that is highly communicable in nature, spreading fast across the globe, and the fact that there is yet to be a known cure for it. The COVID-19 pandemic has caused widespread concern throughout the world, resulting in a global lockdown on social restrictions such as international and national transportation links, market or business transactions, school and organization activities, and all related social and religious gatherings. Back home in Nigeria, the COVID-19 lockdown spanned from early May 2020 to the end of July 2020. Movement was restricted during this period. Gradually, lockdown was eased, but a curfew of $8 \mathrm{pm}$ to $6 \mathrm{am}$ was introduced across major cities in the country to curtail the spread of the virus. This study examined the psychological implications of the COVID-19 pandemic, with a particular focus on a sample of 1000 drawn from across the length and breadth of the country using online data collection channels. The ages of the respondents ranged from 18-50 years. The sample was made up of $42.3 \%$ females and $57.7 \%$ males. The Generalized Anxiety Disorder was assessed using GAD-7 and stress was measured using the Perceived Stress Scale (PSS-10). Analysis of the data was carried out using the Chi Square test and the results show a significantly higher number of females experiencing GAD than their male counterparts, while males suffered more stress than females. Furthermore, findings show that younger and middle-aged people suffered from GAD more than older people, while older people suffered more stress than younger and middle-aged people. It was therefore recommended, among others, that general healthcare professionals should collaborate with psychotherapists in the management of this pandemic and future ones in order to promote people's psychological wellbeing in society. Also, mental health experts should come up with an awareness campaign on the basic means of overcoming psychological distress in the media and in communities generally in Nigeria to foster mental healthiness.
\end{abstract}

Keywords: Psychological Implications; COVID-19; Lockdown and Analysis; Life Quality.

\section{Introduction}

Emerging Infectious Diseases (EIDs) are diseases caused by an infectious pathogen that has recently evolved and entered a population for the first time; or a disease that has previously occurred but whose incidence, impact, and/or geographic range has increased or is expected to increase within a specific timeframe [1-3]. Novel infections in humans, animals, and plants are examples of EIDs. One of the emerging infectious diseases trending now is the coronavirus, which has struck the entire world in the wake of the year 2020, affecting different people in different

* Corresponding author: baki@bsum.edu.ng

doi) http://dx.doi.org/10. 28991/HEF-2020-01-02-04

$>$ This is an open access article under the CC-BY license (https://creativecommons.org/licenses/by/4.0/).

(C) Authors retain all copyrights. 
ways. Most infected people develop mild to moderate illness and may recover without hospitalization and may or may not have the following symptoms; fever, diarrhea, aches and pains, loss of the sense of taste, sore throat, among others [4].

COVID-19, which was initially detected in Wuhan, China, in December 2019, was declared a Public Health Emergency of International Concern in January 2020 and later a pandemic in March 2020 by the World Health Organization (WHO). As of August $30^{\text {th }}, 2020$, barely one year from the day the disease was discovered, the world health organization on this day recorded 1.8 million new COVID-19 cases, 38,000 new deaths were reported, making a cumulative total of nearly 25 million cases and 800,000 deaths globally since the outbreak of the disease [5, 6].

These tribulations and the high mortality rate have created panic as several myths have evolved and revolve about the origin, spread, and the level of damage the pandemic is causing to the world. The prophets of doom sent shivers of worry down the spines of their congregations by declaring the pandemic as the end-of-world disease. On their side, the conspiracy theorists alleged that COVID-19 is an attempt by the world powers to reduce world population by using biological weapons as well as introduce vaccination as a way of inserting digital chips in humans in order to place them under perpetual remote control. Unfortunately, prominent international politicians who were expected to take drastic decisions to halt the spread of the virus instead engaged in blame games, as was the case between the American President, Donald Trump, and the President of the People's Republic of China over where and how the disease emerged. Trump accused Chinese government of using COVID-19 as a chemical weapon to destroy the world economy while the Chinese president denied the allegation (CNN World News, 2020).

Without a doubt, this barrage of disinformation regarding variables like virus transmission, incubation duration, and influence on people's socio-economic, political, and psychological health puts the general public at risk of mental illness. Some of the mental health issues that have been reported due to COVID-19 include anxiety, depression, anger, and confusion. Others are insomnia, post-traumatic disorders, and boredom. Also included in the array of psychological distress are loneliness and adjustment problems. For instance, Wang et al. (2020) [7] found that 53.8\% of Chinese scored moderate to severe on the psychological impacts of the COVID-19 outbreak. Just like $16.56 \%$ reported moderate to severe anxiety symptoms, and $8.1 \%$ reported moderate to severe stress levels. Similarly, Samantha et al. (2020) found negative psychological effects of COVID-19, which included post-traumatic stress symptoms, confusion, and anger, which were due to stressors including longer quarantine duration, infection fears, frustration, boredom, inadequate supplies, inadequate information, financial loss, and stigma. According to Kim et al. (2020) [8], 10-20\% of South Africans experienced anxiety, fear, and "thinking too much" as a result of the COVID-19 pandemic.

In Nigeria, Fehintola (2020) [9] found that mental health distress, abuse of drugs, alongside other psychosocial issues are emanating from the challenges posed by COVID-19 lockdown. Also, Mutanga \& Abayomi (2020) [10] found that while 51\% respondents reported moderate anxiety, 49\% exhibited severe anxiety during the COVID-19 pandemic respectively in Nigeria revealing that Nigerians experienced psychological distress during COVID-19 pandemic. They found the prevalence of psychological factors including insomnia, depression and post-traumatic stress symptoms among Nigerians during the COVID-19 pandemic establishing psychological distress among the general public in Nigeria.

Furthermore, measures to limit the pandemic, such as self-isolation, quarantine, social distance, and treatment of infected persons, can cause psychological distress $[6,11]$. The loneliness impact of less social connections is a risk factor for a variety of psychiatric illnesses, including anxiety, drug use, insomnia, major depression, and suicide thoughts, particularly among vulnerable groups such as the elderly and those with health issues. Excessive quarantine, according to Rubin \& Wessely (2020) [12], has the potential to cause substantial anxiety for a variety of reasons; moreover, heightened anxiety may prompt and initiate the onset of several associated mental health disorders. Barbisch et al. (2015) [13] had previously highlighted the impact of confinement on the public's psychological wellbeing, citing hysteria, rejection and dejection feelings, obsessive-compulsive symptoms, and mood challenges as conditions that can lead to complex health issues in victims and the general public.

Despite the devastating impact that dealing with highly contagious and life-threatening diseases has on healthcare workers in Sub-Saharan Africa, there is concern that the region's government has not paid enough attention to the psychological effects of a pandemic like the corona virus on the region's healthcare workers [14]. Despite financial and infrastructure support from both local and international groups, it has been claimed that the Nigerian government pays little or no attention to the psychological well-being of healthcare workers on the front lines of the corona virus epidemic (WebNews, 20 ${ }^{\text {th }}$ April, 2020).

Owing to the overwhelming psychological effects of this pandemic on the world, Nigeria and particularly Benue State residents without much research to address the alarming impacts, it has therefore become paramount to carry out this study to have more insight into the problem so as to adopt appropriate psychological interventions avert same. Hence, there is need to analyze psychological implications of the outbreak of COVID-19 among Nigerians. 
Thus, it was hypothesized as follows:

i. There will be a significant gender and age difference in the prevalence of anxiety symptoms among Nigerians during the COVID-19 pandemic.

ii. There will be a significant gender and age difference in the prevalence of stress symptoms across among Nigerians amid COVID-19 pandemic.

\section{Method}

\subsection{Design}

The descriptive survey research design was employed in the study. This design was found appropriate to describe the psychological distress suffered by Nigerian amid COVID-19 pandemic. This method allowed for the use of questionnaires to assess symptoms of Generalized Anxiety Disorder and stress.

\subsection{Sampling}

A snowballing sampling technique was used in this study due to the lockdown that led to the restriction movement which made it very difficult to physically access people at the time of data collection. Online structured questionnaires were administered using Google forms, with a consent form appended to it. The link of the questionnaire was sent through emails, WhatsApp and other social media to people on the contact of the researcher. The prospective respondents were then encouraged to share out the survey to as many of their contacts as possible. Thus, the link was forwarded to people apart from the first point of contact and so on.

\subsection{Participants}

The participants were 1000 in total consisting of 423 females (42.3\%) and 577 males (57.7\%) within the ages of 18-28, 29-39, 40-50 and above. The marital status of the participants was also observed on the levels of single, married, divorced and others. Other demographic indicators included the questions like do you have a steady family income, do you have long term health problems, do you have a relative or someone you know suspected of being infected with covid-19.

\subsection{Instruments}

Data were collected via online self-reported questionnaires. The questionnaire assessed the level of psychological distress among generality of Nigerians during the COVID-19 lockdown. The first section consisted of information assessing demographic attributes such as sex, age and marital status of the respondents. The second section contained the GAD-7 developed by Spitzer et al. (2006) [15] consisting of 7 questions assessing Generalized anxiety disorder, focusing on the frequency of symptoms during the preceding 2-week period. The GAD-7 requires approximately 1-2 minutes administering and for each symptom queried provides the following response options: "not at all," "several days," "over half the days" and "nearly every day" and these are scored, respectively, as 0, 1, 2 or 3. A score ranging from 0 to 21 is obtainable by respondents. Scores of 5, 10, and 15 are taken as the cut-off points for mild, moderate and severe anxiety, respectively. Cronbach's alpha 0.81 was established as the reliability coefficient for the scale in this study. The third section contained the Perceived Stress Scale (PSS-10). PSS-10 is a 10-item questionnaire designed by Cohen et al. (1983) [16] to evaluate the self-reported amount of stress in the participants by assessing thoughts and feelings in the previous month. Each question is scored from 0 (never) to 5 (very often) with a total possible score range of 0 to 40 . A higher score indicates a high level of stress.

\subsection{Procedure}

This was a web-based research. Participants having internet access were asked to take part in the study. Participants had to be at least 18 years old, able to communicate in English, and ready to give informed permission. All participants received a link to the Google form survey. Participants were automatically routed to research material after receiving and clicking the link. At the start of the online questionnaire, a thorough informed consent form was included, and consent was required to proceed. As a result, only those who granted their consent participated in this study. The data collection was initiated on $14^{\text {th }}$ April 2020 and closed on $15^{\text {th }}$ May 2020. The sampling technique employed allowed the researcher to collect data from across various states of Nigeria. One thousand correctly filled questionnaire were recovered through the Google form and processed for statistical analysis. 


\subsection{Data Analysis}

The collected data was analyzed using the SPSS package (version 20). Hypotheses were tested using Chi-Square test and the results present in bar charts.

\section{Results}

The data collected were analyzed using Case Chi-Square test and the results are presented in Figures 1 to 4 as seen below. The results in Figure 1 indicated that 33.1, 21.0 and $8.5 \%$ of the female respondents surveyed suffered mild, moderate and severe generalized anxiety disorder respectively while $37.4 \%$ of them were free from GAD. Comparatively, 31.5, 22.0 and 4.5\% males experienced mild, moderate and severe GAD accordingly while $41.9 \%$ were not victims. Further analysis using Chi-Square test indicated that there is a significant higher incidences of GAD among females than male Nigerians $\left(X^{2}=(d f=3)=7.887, p=.05\right)$. This implies that gender is one of the major factors implicated in the incidence of GAD among the general population in the times of adversity.

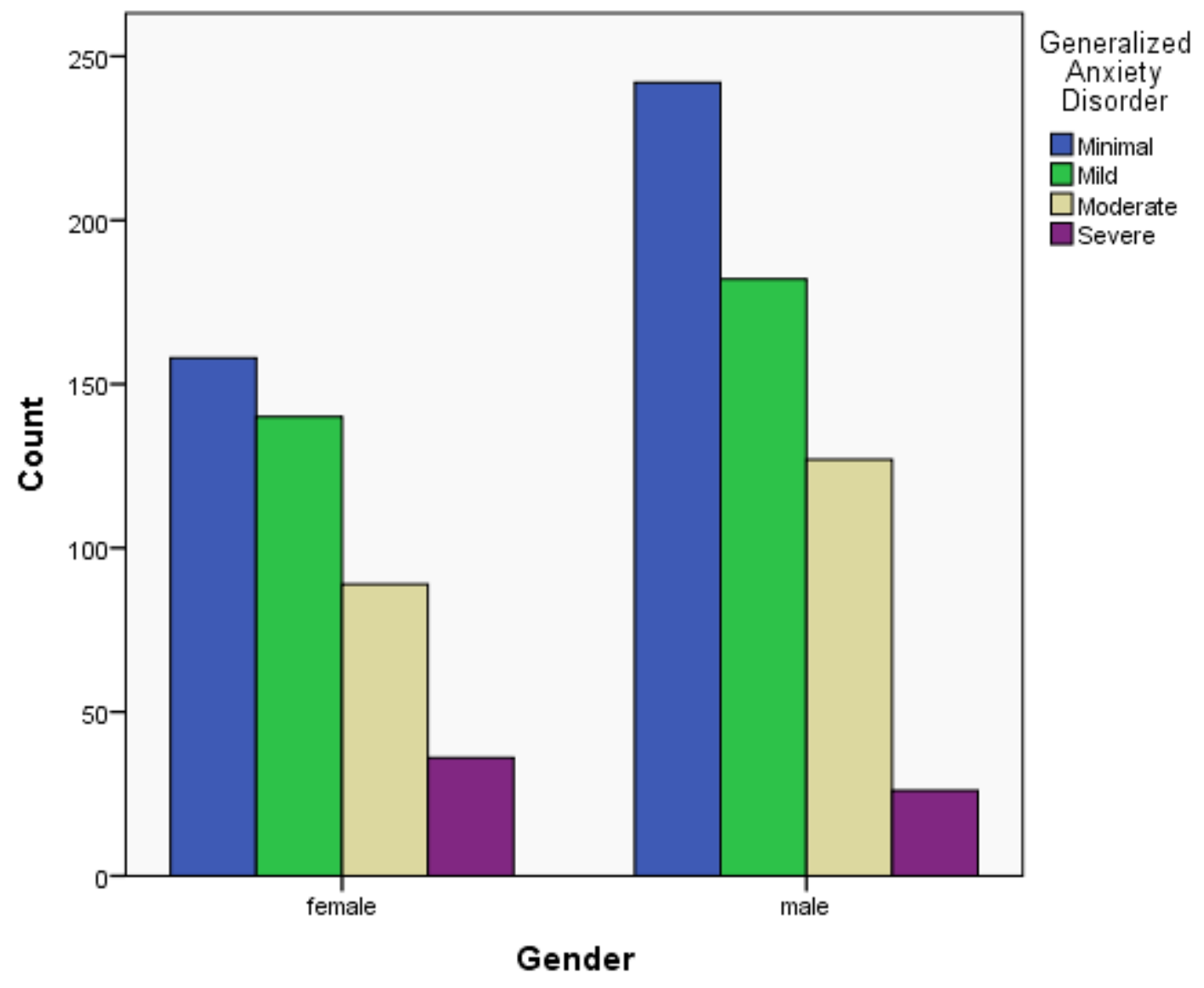

Figure 1. Bar chart showing gender difference in prevalence of GAD among Nigerians COVID-19 lockdown

The results in Figure 2 revealed that 52.0 and $14.2 \%$ of the female respondents lamented suffering moderate and high level of stress respectively while $33.8 \%$ of them reported experiencing low level of stress during COVID-19 lockdown. On the side of the male respondents, $63.6 \%$ perceived moderate stress, $12.8 \%$ reported suffering high level of stress and $23.6 \%$ reported experiencing low level of stress. Furthermore, Chi-Square test showed that there was a significant higher incidences of stress among males than female Nigerians $\left(X^{2}=(d f=2)=15.093, p<0.05\right)$. This implies that gender is one of the major factors implicated in the incidence of stress among the general population in the times of adversity.

The results in Figure 3 indicated that 44.7, 16.7 and $6.1 \%$ of the younger respondents (18-28 years old) sampled suffered mild, moderate and severe generalized anxiety disorder respectively while $32.5 \%$ were not victims of GAD. Also, 24.8, 28.5 and $8.9 \%$ of the middle aged (29-39 years old) experienced mild, moderate and severe GAD respectively while $37.8 \%$ were not victims. Furthermore, $31.7,10.3$ and $52.6 \%$ of the older respondents (40 and above years) experienced mild, moderate and no GAD respectively. Further analysis using Chi-Square test indicated that there is a significant higher incidences of GAD among the younger and middle aged Nigerian than their order counterparts $\left(X^{2}=(d f=6)=83.906, p<.001\right)$. This implies that younger and middle aged Nigerians suffered GAD more than the older populations who were more relaxed during the lockdown. 


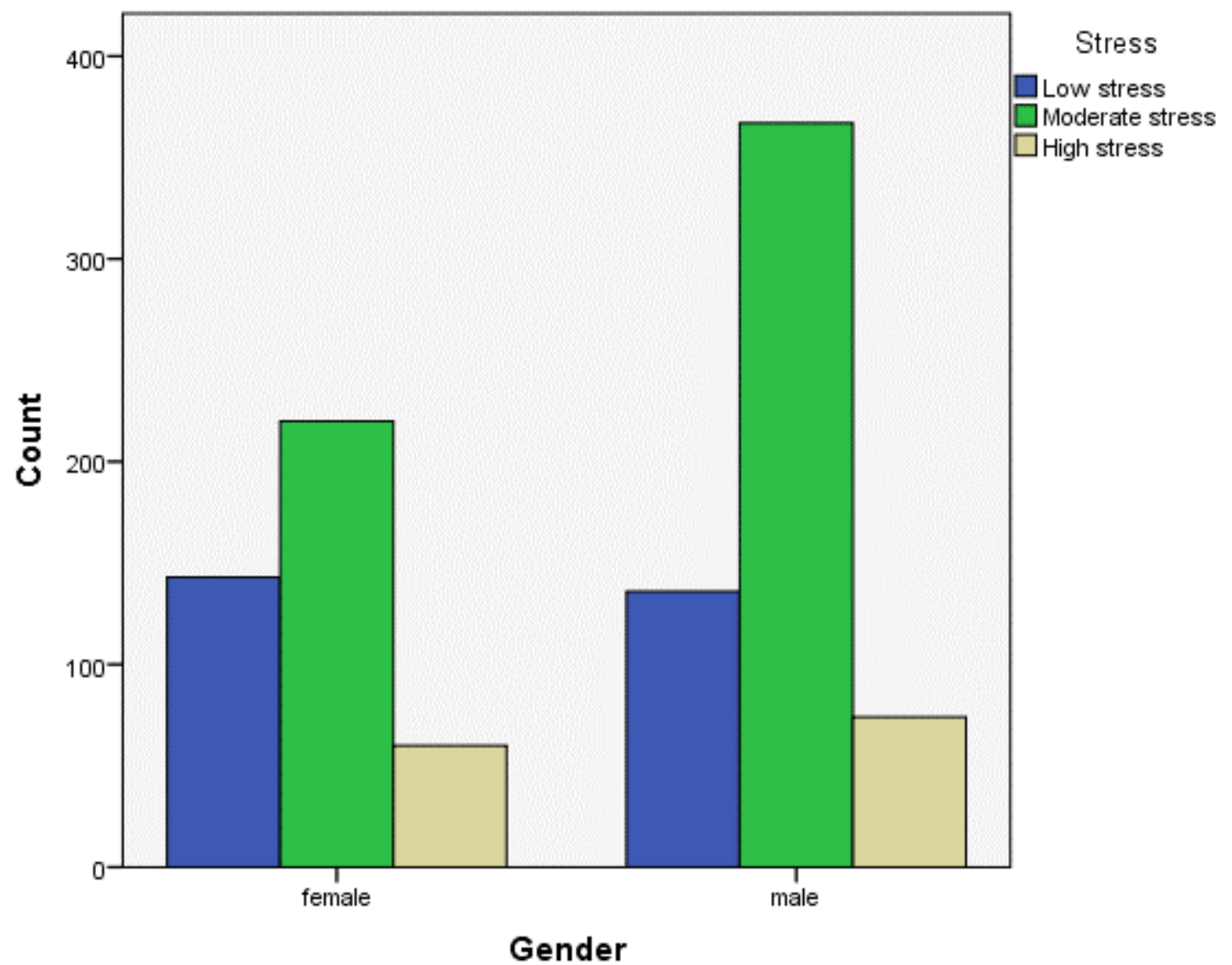

Figure 2. Bar chart showing gender difference in perceived stress among Nigerian during the COVID-19 lockdown

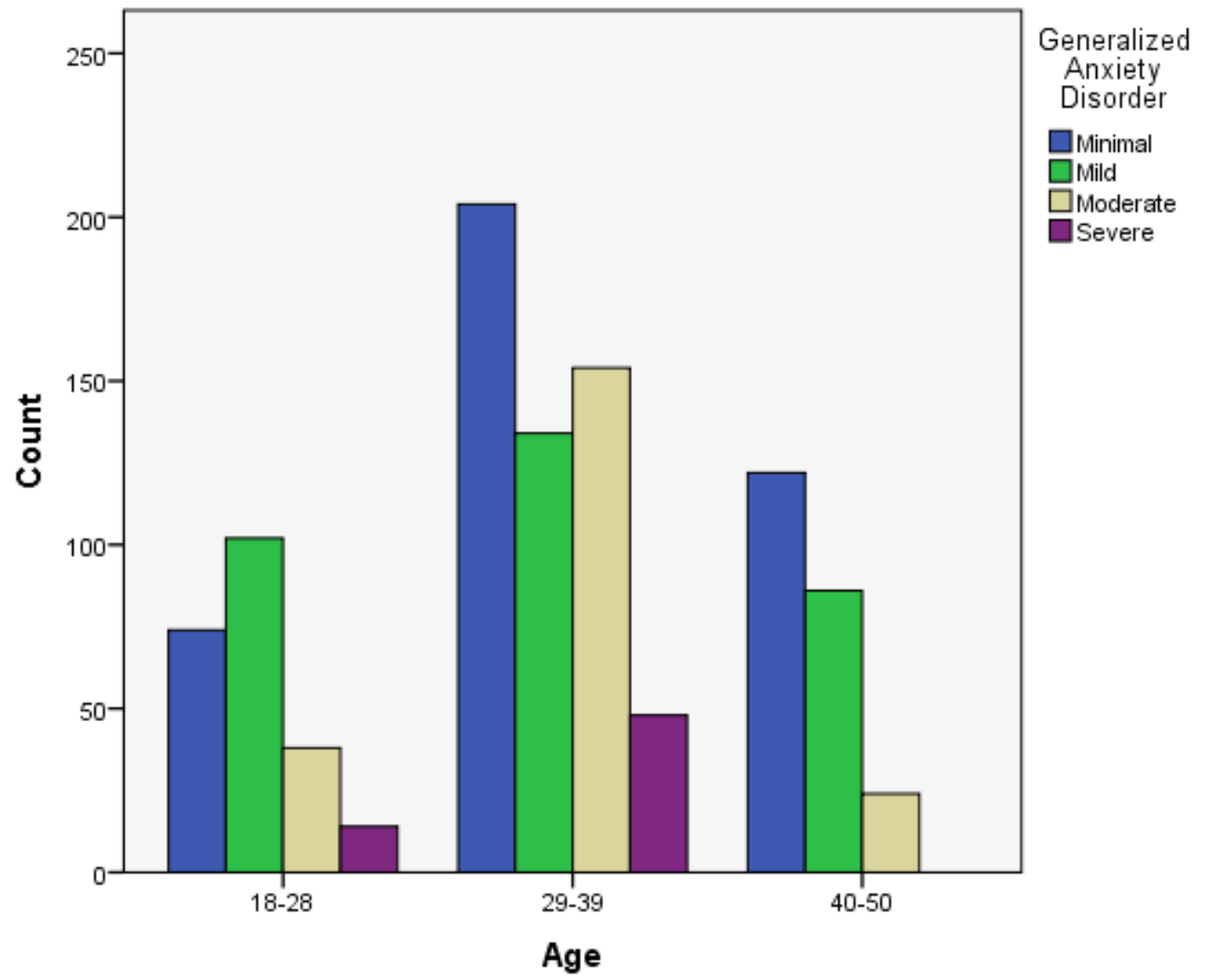

Figure 3. Bar chart showing age difference in the incidences of GAD among Nigerian during the COVID-19 lockdown 
The results in Figure 4 showed that 43.9 and $16.7 \%$ of the younger respondents (18-28years old) experienced moderate and high level of stress respectively while 39.5\% experienced low level of stress. Also, 63.5 and $11.1 \%$ of the middle aged (29-39 years old) experienced moderate and high levels of stress respectively while $25.4 \%$ had experienced low stress during the lockdown. Furthermore, 62.1, 15.5 and $22.4 \%$ of the older respondents (40 and above years) had experienced moderate high and low levels of stress respectively. Further analysis using Chi-Square test revealed that there was a significant higher incidences of stress among the middle aged and older Nigerian than their younger counterparts $\left(X^{2}=(d f=4)=30.530, p<.001\right)$. This implies that middle aged and older Nigerians suffered more stress than the younger populations during the lockdown.

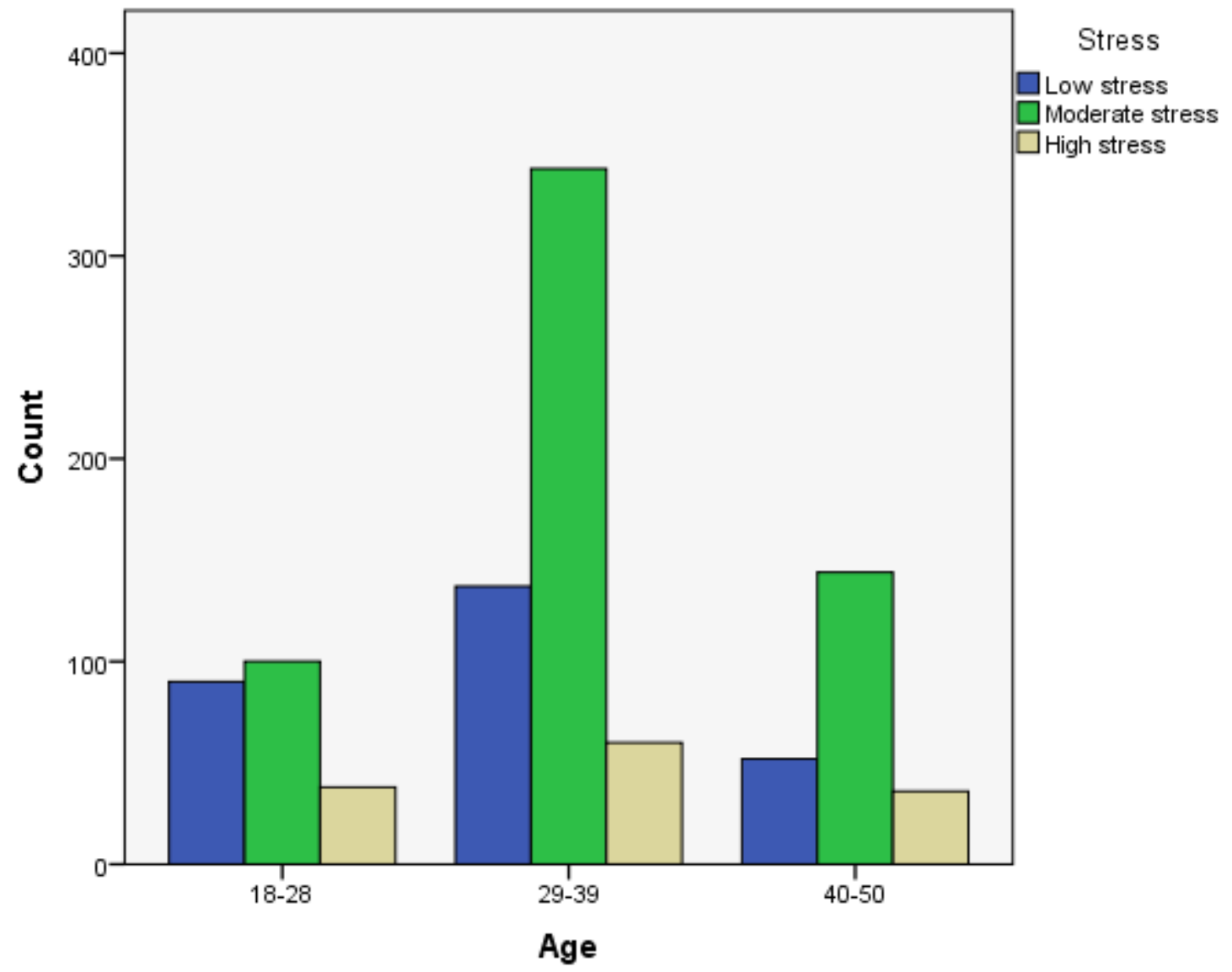

Figure 4. Bar chart showing age difference in stress experiencing by Nigerians during the COVID-19 lockdown

\section{Discussion of Findings}

It is a well-known fact that Nigeria like other countries of the world has experienced several outbreaks of dreaded novel diseases such as Ebola virus, HIV/AIDS, Lassa fever, tuberculosis and monkey pox among several others and yet, Nigerians were resilient enough that they thrived above all these emergencies (Nigerian Centre for Disease Control, 2020). This notwithstanding, the outbreak of COVID-19 was the most devastating pandemic that had overwhelmed Nigeria in particular and the global community in general leading to total lockdown with its attendant consequences. The new COVID-19 pandemic has ushered in great disruption in human activities and habits that created adjustment challenges to Nigerians culminating into psychological distress.

Specifically, findings of this study have shown that the lockdown, physical and social distancing, closure of schools and the compulsory use of face/nose mask have created adjustment problems thus making many people vulnerable to negative psychological effects. Amidst the fear and risk of contagion of the COVID-19, the changes in the day to day activities of so many Nigerians have caused prevailing psychological distresses. For instance, this study revealed that there was a significant incidence of GAD among Nigerians; with female gender recording higher incidences of GAD than their male counterparts. Specifically, results have shown that 33.1, 21.0 and $8.5 \%$ of the female respondents who participated in the study suffered mild, moderate and severe generalized anxiety disorder respectively while $37.4 \%$ of them were free from GAD. As compared to the females, 31.5, 22.0 and 4.5\% male respondents were found to have experienced mild, moderate and severe GAD accordingly, while $41.9 \%$ were lucky escapes. This means that females are pathologically more anxious when faced with death threat to the magnitude of COVID-19 pandemic. This implies that female tend to suffer more emotional adjustment problems than their male counterpart who exhibit greater emotional strengths. 
Given the marginalisation of women in Nigeria's societal structure, this conclusion is unsurprising. In Nigeria, for example, adult females and even youngsters (females) offer unpaid care to families, which includes cooking, washing, child care, and general housekeeping [17]. Due to the lockdown, stay at home order of the Federal Government and cleaning of surfaces mantra, most female household chores have been doubled or tripled in most cases, and this can be distressing. Domestic violence against women and girls has increased, prompting Amina Mohammed (UN Deputy Secretary-General) to call on all governments, civil society organisations, and people to address gender-based violence as a major problem in all domestic COVID-19 response plans [18]. According to Daniels (2020) [19], due to the restrictions on mobility and lockdown in most parts of the nation, many women in Nigeria, particularly those in abusive marriages and relationships, have no way out. In light of this, it's not surprising to find that women have a greater rate of Generalized Anxiety Disorder.

This finding is consistent with the previous findings on women in eight other countries across Africa and Asia which showed that women reported higher sleep problems than men based on the series of roles they play in families; more females than their male counterparts were confirmed to be susceptible to insomnia and high posttraumatic stress symptoms [20-22]. Similar findings indicate that 15\% experience insomnia (moderate to severe). A Korean population reported an overall prevalence of insomnia symptoms of $10.7 \%$, which included difficulty in initiating sleep, difficulty in maintaining sleep and early morning awakening, but the symptoms were more prevalent in females than in males [23]. Thus, it is clear that both the previous findings and the current finding have shown that the female gender is more emotionally vulnerable than their male counterpart in the face of adversity.

With regards to gender differences in the experience of stress during the COVID-19 lockdown, results have shown that there was a significantly higher incidence of stress among males than female Nigerians. More specifically, findings indicated that 52.0 and $14.2 \%$ of the female respondents suffered moderate and high levels of stress, respectively, while $33.8 \%$ of them reported experiencing a low level of stress during the COVID-19 lockdown. As compared to the females, $63.6 \%$ of the males experienced moderate stress, $12.8 \%$ reported suffering a high level of stress, and $23.6 \%$ reported experiencing a low level of stress.

This implies that the male gender, which bears the responsibility of wading off adversity that befalls mankind, is more likely than women to suffer tension and other forms of stress associated with their masculine role in society. In Nigeria, being a masculine-dominated country, men shoulder the family responsibilities at all times, thereby subjecting themselves to more stressful life events than women. This finding is consistent with the submission of Fehintola (2020) [9], which showed that mental health distress, abuse of drugs, and other psychosocial issues are emanating from the challenges posed by COVID-19 lockdown, most especially among men who indulged in maladaptive coping.

Furthermore, findings from this study on age, generalised anxiety disorder, and stress revealed that there was a significantly higher incidence of GAD among the younger and middle-aged Nigerians than their order counterparts. Whereas, one leg of the findings revealed that there was a significantly higher incidence of stress among the middleaged and older Nigerians than their younger counterparts. This implies that younger and middle-aged Nigerians suffered GAD more than the older populations, while the older and middle-aged Nigerians suffered more stress than the younger populations during the lockdown.

These findings are consistent with recent past studies affirming the high and huge level of psychosocial consequences of outbreaks like COVID-19 on individuals, the general public, and the international community [7, 24]. For example, during the SARS pandemic, Leung (2003) [25] observed that many of those who were tested on the psychological consequences exhibited significant psychological difficulties that were linked to young people and increased self-blaming. While those older people who were females and highly educated, displayed higher anxiety feelings for SARS positivity, while the less educated had a moderate anxiety rate; those with known contact history with the infected individuals, perceived they have symptoms of SARS and have more tendency to indulge in preventive measures against the disease.

\section{Conclusion}

In conclusion, the study findings revealed that the incidence of GAD and stress symptoms among Nigerians during the COVID-19 pandemic lockdown were high. Findings clearly indicated that there were significant gender and age differences in the manifestations of GAD and stress among the respondents. Higher incidences of GAD were found in females more than in males, while males reported higher incidences of stress than females. With regards to age, it was concluded that the younger and middle-aged people were more anxious than the older people, while the older people were found to be more stressed than the younger people. Thus, there is a need for the governments at all levels in Nigeria to make available, if not for all, psychological health services for survivors of the COVID-19 pandemic.

\subsection{Limitation of the Study}

The study sampled only 1000 Nigerians, which is relatively small to ascertain the generalizability of the current findings. It may be possible that findings change if a larger sample is used. Some psychological factors such as 
depression and post-traumatic stress disorder, among others, should have been included in this study to have a variety of findings. Finally, the issue of response bias, which is a shortcoming in self-reported surveys, could have influenced the study outcome.

\subsection{Recommendations}

Considering the findings of this study, the following are suggested in order to enhance psychological wellbeing among Nigerians during the pandemic period:

i. The government, NGOs, and CBOs should always involve psychological health service providers in the fight against the present and future pandemics or any disease outbreak in the country.

ii. Healthcare professionals should collaborate with psychotherapists in the management of this pandemic and future ones in order to promote people's psychological wellbeing in society.

iii. Mental health experts should come up with an awareness campaign on the basic means of overcoming psychological distress in the media and in communities generally in Nigeria to foster mental healthiness.

\section{Declarations}

\subsection{Author Contributions}

Conceptualization, B.D.A. and E.L.; methodology, B.D.A., E.L., S.N.H., O.M.O., and T.R.T.; writing-original draft preparation, B.D.A., E.L., S.N.H., O.M.O., and T.R.T.; writing-review and editing, B.D.A., E.L., S.N.H., O.M.O., and T.R.T. All authors have read and agreed to the published version of the manuscript.

\subsection{Ethical Approval}

In accordance with the Declaration of Helsinki, the participants were provided with information about the aim and the course of the study and expressed their written and informed consent to participate. The persons were informed about the possibility of withdrawing from the study at any stage of the interview.

\subsection{Data Availability Statement}

The data presented in this study are available on request from the corresponding author.

\subsection{Funding}

The authors received no financial support for the research, authorship, and/or publication of this article.

\subsection{Declaration of Competing Interest}

The authors declares that there is no conflict of interests regarding the publication of this manuscript. In addition, the ethical issues, including plagiarism, informed consent, misconduct, data fabrication and/or falsification, double publication and/or submission, and redundancies have been completely observed by the authors.

\section{References}

[1] Jones, K. E., Patel, N. G., Levy, M. A., Storeygard, A., Balk, D., Gittleman, J. L., \& Daszak, P. (2008). Global trends in emerging infectious diseases. Nature, 451(7181), 990-993. doi:10.1038/nature06536.

[2] Nigeria Centre for Disease Control, (2020). Disease Information. Available online: https://ncdc.gov.ng/diseases/a-z (accessed on March 2020).

[3] Morse, S. S., \& Schluederberg, A. (1990). Emerging viruses: the evolution of viruses and viral diseases. The Journal of infectious diseases, 162(1), 1-7.

[4] World Health organization (WHO). Weekly epidemiology update on corona virus disease (COVID-19). Available online: https://www.who.int/emergencies/diseases/novel-coronavirus-2019/situation-reports (accessed on March 2020).

[5] World Health Organization (WHO). There is a current outbreak of Corona virus (COVID-19) disease. Available online: https://www.who.int/health-topics/coronavirus\#tab=tab_1 (accessed on March 2020).

[6] World Health Organization (WHO). Mental Health and psychological considerations during the Covid-19 outbreak. Available online: https://www.who.int/docs/default-source/coronaviruse/mental-health-considerations.pdf (accessed on March 2020).

[7] Wang, C., Pan, R., Wan, X., Tan, Y., Xu, L., Ho, C. S., \& Ho, R. C. (2020). Immediate Psychological Responses and Associated Factors during the Initial Stage of the 2019 Coronavirus Disease (COVID-19) Epidemic among the General Population in China. International Journal of Environmental Research and Public Health, 17(5), 1729. doi:10.3390/ijerph17051729. 
[8] Kim, A. W., Nyengerai, T., \& Mendenhall, E. (2020). Evaluating the mental health impacts of the COVID-19 pandemic: perceived risk of COVID-19 infection and childhood trauma predict adult depressive symptoms in urban South Africa. Psychological Medicine, 1-13. doi:10.1017/s0033291720003414.

[9] Fehintola, J. O., \& Fehintola, R. O. (2020). Assessment of impact of covid-19 challenges on psychosocial well-being of Nigerians. European Journal of Education Studies, 7(5), 21-33.

[10] Mutanga, M. B., \& Abayomi, A. (2020). Tweeting on COVID-19 pandemic in South Africa: LDA-based topic modelling approach. African Journal of Science, Technology, Innovation and Development, 1-10. doi:10.1080/20421338.2020.1817262.

[11] Fiorillo, A., \& Gorwood, P. (2020). The consequences of the COVID-19 pandemic on mental health and implications for clinical practice. European Psychiatry, 63(1). doi:10.1192/j.eurpsy.2020.35.

[12] Rubin, G. J., \& Wessely, S. (2020). The psychological effects of quarantining a city. BMJ, M313. doi:10.1136/bmj.m313.

[13] Barbisch, D., Koenig, K. L., \& Shih, F.-Y. (2015). Is There a Case for Quarantine? Perspectives from SARS to Ebola. Disaster Medicine and Public Health Preparedness, 9(5), 547-553. doi:10.1017/dmp.2015.38.

[14] Higgins, A. (2014). Ebola fight in Africa is hurt by limits on ways to get out'. New York Times, United States.

[15] Spitzer, R. L., Kroenke, K., Williams, J. B. W., \& Löwe, B. (2006). A Brief Measure for Assessing Generalized Anxiety Disorder. Archives of Internal Medicine, 166(10), 1092. doi:10.1001/archinte.166.10.1092.

[16] Cohen, S., Kamarck, T., \& Mermelstein, R. (1983). A Global Measure of Perceived Stress. Journal of Health and Social Behavior, 24(4), 385-396. doi:10.2307/2136404.

[17] Sandoiu, A. (2020). How COVID-19 affects women's sexual and reproductive health. MEDICALNEWSTODAY. Available online: https://www.medicalnewstoday.com/articles/how-covid-19-affects-womens-sexual-and-reproductive-health (accessed on February 2020).

[18] United Nations (2020). UN backs global action to end violence against women and girls amid COVID-19 crisis. UN News. Available online: https://news.un.org/en/story/2020/04/1061132 (accessed on March 2020).

[19]Daniels, N. (2020). Women are suffering domestic violence because of COVID-19. Available online: https://www.askifa.ng/women-are-suffering-domestic-violence-because-of-covid-19/ (accessed on March 2020).

[20] Liu, N., Zhang, F., Wei, C., Jia, Y., Shang, Z., Sun, L., ... Liu, W. (2020). Prevalence and predictors of PTSS during COVID19 outbreak in China hardest-hit areas: Gender differences matter. Psychiatry Research, 287, 112921. doi:10.1016/j.psychres.2020.112921.

[21] Stranges, S., Tigbe, W., Gómez-Olivé, F. X., Thorogood, M., \& Kandala, N.-B. (2012). Sleep Problems: An Emerging Global Epidemic? Findings From the INDEPTH WHO-SAGE Study Among More Than 40,000 Older Adults From 8 Countries Across Africa and Asia. Sleep, 35(8), 1173-1181. doi:10.5665/sleep.2012.

[22] Zhang, B., \& Wing, Y.-K. (2006). Sex Differences in Insomnia: A Meta-Analysis. Sleep, $29(1), 85-93$. doi:10.1093/sleep/29.1.85.

[23] La, Y. K., Choi, Y. H., Chu, M. K., Nam, J. M., Choi, Y.-C., \& Kim, W.-J. (2020). Gender differences influence over insomnia in Korean population: A cross-sectional study. PLOS ONE, 15(1), e0227190. doi:10.1371/journal.pone.0227190.

[24] Hall, R. C. W., Hall, R. C. W., \& Chapman, M. J. (2008). The 1995 Kikwit Ebola outbreak: lessons hospitals and physicians can apply to future viral epidemics. General Hospital Psychiatry, 30(5), 446-452. doi:10.1016/j.genhosppsych.2008.05.003.

[25] Leung, C. M., \& Lam, S. F. (2003). The effects of regulatory focus on teachers' classroom management strategies and emotional consequences. Contemporary Educational Psychology, 28(1), 114-125. doi:10.1016/s0361-476x(02)00009-7. 